\title{
Traumatic pericardial tamponade: relearning old lessons
}

\author{
R Crawford, H Kasem, A Bleetmen
}

\begin{abstract}
Traumatic pericardial tamponade is a serious and rapidly fatal injury. As penetrating chest wounds are becoming more common, early diagnosis of tamponade is important so that life saving treatment can be started. The classical features of tamponade may be modified by hypovolaemia and the presence of associated injuries; acute tamponade may also be precipitated by rapid administration of large volumes of fluid. Pericardiocentesis, while sometimes life saving, is dangerous and of limited value. Echocardiography is limited by availability and operator dependence. A high degree of clinical suspicion in patients with chest injuries, together with close monitoring and reevaluation, particularly during volume replacement, is essential. Four cases are described which presented to the accident and emergency department of Glasgow Royal Infirmary, in three of which there was a significant delay in the diagnosis. ( $¥$ Accid Emerg Med 1997;14:252-254)
\end{abstract}

Keywords: traumatic pericardial tamponade; chest wounds; treatment

The majority of patients who arrive at hospital following a penetrating injury to the heart will have no vital signs. ${ }^{1}$ Among those that do, up to $16 \%$ will be relatively stable and there will not be any indication of their serious underlying injury. ${ }^{2}$ Pericardial tamponade is a life threatening complication of penetrating cardiac trauma that will lead to rapid deterioration in a patient's condition and require emergency treatment. ${ }^{3}$ It is important to identify and treat this group of patients before deterioration occurs. Classically the diagnosis is suspected from the presence of hypotension, distended neck veins, and muffled heart sounds, known as Beck's triad. ${ }^{4}$ However, these signs are not present in many patients or are attenuated, making recognition more difficult. We present four patients who attended the accident and emergency (A\&E) department of Glasgow Royal Infirmary with traumatic cardiac tamponade - in three of whom there was a significant delay in diagnosis - and we review the difficulties in the management of this clinical problem.

\section{Case 1}

A 23 year old male was brought to the $A \& E$ department after having been stabbed in the anterior chest wall and the left loin. On admission he was conscious, with a pulse rate of 110 beats/min and a blood pressure $90 / 60 \mathrm{~mm} \mathrm{Hg}$. Heart sounds were recorded as normal and he had good bilateral air entry into the chest. Fluid resuscitation was begun immediately with $1500 \mathrm{ml}$ of crystalloid solution, and a chest $x$ ray was performed. He was referred to the on-call general surgical registrar who saw the patient 40 minutes after admission. At that stage he had become cold and clammy and was complaining of chest pain; his pulse had risen to $150 / \mathrm{min}$ and the blood pressure had fallen to $70 / 50 \mathrm{~mm} \mathrm{Hg}$. His heart sounds were muffled and neck veins were noted to be distended. His chest $x$ ray revealed no evidence of a pneumothorax or haemothorax, but the cardiac silhouette was enlarged. Tamponade was suspected and echocardiography revealed a $1 \mathrm{~cm}$ rim of fluid in the pericardial space. He was taken to theatre and underwent thoracotomy. Five hundred millilitres of blood were evacuated from his pericardial space and a $1 \mathrm{~cm}$ laceration of the right ventricle repaired. The postoperative course was uncomplicated and he was discharged six days later.

\section{Case 2}

A 49 year old man was brought to the A\&E department with multiple stab wounds to his occiput, anterior chest, and epigastrium. $\mathrm{He}$ was heavily intoxicated with alcohol and had a pulse rate of $90 / \mathrm{min}$ and a blood pressure of $100 / 70 \mathrm{~mm} \mathrm{Hg}$. The neck veins were not noted to be distended and clear heart sound were heard. Immediate fluid resuscitation was instituted and a chest $x$ ray showed no evidence of intrathoracic injury. As there was some concern over his abdominal injuries he was taken to theatre and underwent exploratory laparotomy but no significant organ injury was found. Postoperatively he became oliguric and on re-examination was noted to be hypotensive with a blood pressure of $90 / 70 \mathrm{~mm} \mathrm{Hg}$ and a pulse rate of $100 / \mathrm{min}$. Central venous pressure was normal at $7 \mathrm{~cm} \mathrm{H}_{2} \mathrm{O}$. Despite further administration of fluids his urine output remained poor and his central venous pressure rose to $25 \mathrm{~cm}$. A diagnosis of tamponade was suspected some 12 hours after admission and 
echocardiography confirmed the presence a 2 $\mathrm{cm}$ fluid rim, with significant compromise of right ventricular function. $\mathrm{He}$ was taken to theatre where the tamponade was relieved and a $7 \mathrm{~mm}$ wound in the right ventricle repaired. Postoperatively he made a good recovery and was discharged five days later.

\section{Case 3}

A 31 year old male was seen in the A\&E department with multiple small stab wounds to his anterior chest, upper abdomen, and left arm. He smelt strongly of alcohol and though conscious was uncooperative and physically and verbally abusive to staff. His vital signs were stable with a pulse rate of $90 / \mathrm{min}$ and blood pressure of $150 / 70 \mathrm{~mm} \mathrm{Hg}$. Arterial blood gases revealed no evidence of hypoxia. Chest $x$ rays were normal and he was transferred to the ward for observation. Three hours later he complained of increasing left pleuritic chest pain and repeat radiography showed a haemothorax. A chest drain was inserted and $900 \mathrm{ml}$ of blood drained out in five minutes, with no further drainage. Immediately after this he was given intravenous opiates for analgesia, but then had a cardiorespiratory arrest which responded rapidly to external cardiac compression and naloxone. Tamponade was suspected, and echocardiography performed. This revealed a small "sympathetic effusion" with no evidence of ventricular compromise, and the episode attributed to overdose with opiate. Over the next few hours he had further short self terminating "apnoeic" episodes. His vital signs remained otherwise stable. The on-call general surgical team were asked to review him and immediately following their arrival he had a cardiorespiratory arrest from which he was again successfully resuscitated. An intrathoracic injury was suspected and the cardiothoracic surgeons were called. Before their arrival he sustained another cardiac arrest. He was intubated and an emergency thoracotomy performed in the ward. A pericardial tamponade was evacuated and a 1.5 $\mathrm{cm}$ laceration in the left ventricle repaired. Postoperatively he did well and was discharged five days later.

\section{Case 4}

A 32 year old man was brought to the A\&E department by ambulance as a "standby". He had been found in a lift and was noted to be cyanosed and unable to give a history. The ambulance crew initially suspected a grand mal seizure but rapidly recognised he was critically ill and suspected a tension pneumothorax when they discovered a $4 \mathrm{~mm}$ wound in the anterior axillary fold above and lateral to the right nipple. It was subsequently discovered that the patient had been stabbed with a screwdriver while in the lift with a man he had apprehended trying to break into a car. They decided to "scoop and run" and on arrival in the emergency department the patient was noted to be suffused and cyanosed in the upper part of his body and pale and white below the nipples. His eyes were bulging and his neck veins were grossly distended. He was agitated and had great difficulty trying to speak. His respiratory rate was $28 / \mathrm{min}$ and bilateral air entry into the chest was noted. His pulse rate was $140 / \mathrm{min}$ and blood pressure was recorded at $150 / 80 \mathrm{~mm} \mathrm{Hg}$. An ECG revealed sinus tachycardia. Arterial blood gases confirmed a profound metabolic acidosis. A diagnosis of acute cardiac tamponade was made and an immediate chest $x$ ray showed an increased cardiothoracic ratio with no evidence of a pneumothorax. While awaiting the arrival of the cardiothoracic surgeons and the anaesthetist a pericardiocentesis was performed with ECG monitoring, using the standard technique taught by the American College of Surgeons advanced trauma life support programme. Eighty millilitres of blood were aspirated, with immediate improvement in the patient's condition. The pulse rate fell to $100 / \mathrm{min}$, the blood pressure fell to $120 / 80 \mathrm{~mm}$ $\mathrm{Hg}$, and his colour improved. The patient was then anaesthetised and underwent immediate emergency thoracotomy through a median sternotomy in the resuscitation room. A large pericardial tamponade was evacuated and the source of bleeding was found to be a puncture wound in the pulmonary artery, which was repaired with a purse string suture. The patient made an uncomplicated recovery and was discharged on the sixth postoperative day.

\section{Discussion}

Penetrating chest wounds are uncommon in the United Kingdom. The incidence varies between hospitals, but Glasgow Royal Infirmary deals with a large number of cases in comparison to other institutions. ${ }^{56}$ Despite this, recognition of cardiac tamponade can still cause difficulty, as these cases illustrate. In a review of emergency thoracotomies performed over a two and a half year period, four $(80 \%)$ out of five pericardial tamponades were initially missed in 16 patients with penetrating cardiac injuries. ${ }^{6}$ This is partly because the patients are relatively stable in the early stages and diagnosis may be difficult due to the presence of alcohol or other injuries which mask subtle clinical features. The diagnosis requires experience and a high degree of clinical suspicion. Significant hypotension must always be explained and frequent re-evaluation of the patient by experienced medical staff is essential.

In this hospital patients with blunt and penetrating chest trauma not requiring thoracotomy are usually managed by the $A \& E$ medical staff and admitted under the care of the A\&E consultants. Those patients with continuing haemorrhage or suspected cardiac trauma are referred directly to cardiothoracic surgeons. General surgeons therefore have limited experience of chest trauma and the opportunity of general surgical trainees to gain experience of these cases is still relatively small. Despite this, a significant number of patients are treated by general surgeons because of concomitant or suspected intra-abdominal injury, particularly when the initial evaluation fails to reveal an obvious intrathoracic injury. 
Chest wounds have been divided into two broad categories-central and peripheralbased on the likelihood of injury to the heart and other major mediastinal structures. The borders of the central zone are the suprasternal notch and the medial halves of the clavicle superiorly, the midclavicular lines laterally, and the xiphoid and costal cartilages inferiorly. ${ }^{7}$ Wounds within these boundaries should raise the suspicion of serious cardiac injury. Three of our cases had stab wounds within this "danger area". However, case 4 shows that the converse of this statement is not true, and any chest wound can result in central organ damage as its extent and trajectory cannot be determined by inspection, and local wound exploration is unreliable and may be dangerous.

Associated injuries may distract attention from the chest, particularly if the patient appears stable. This was best demonstrated in the second patient where it was not until the development of oliguria, following a negative exploratory laparotomy for an abdominal wound, that the correct diagnosis was made.

The pathophysiology of tamponade is related to the impairment of ventricular filling caused by the presence of blood in the pericardial space, leading to raised end diastolic filling pressure and impairment of venous return. This should be evident from distension of neck veins or raised central venous pressure. In patients who are hypovolaemic or have peripheral vasodilatation due to alcohol this sign is often attenuated or absent until adequate volume replacement has been given, as happened in the first case. ${ }^{8}$ It may be argued that standard advanced trauma life support teaching, which advocates rapid volume replacement in trauma patients, may precipitate tamponade in those who would otherwise have been stable. There is growing evidence to support this point of view ${ }^{9}$ and some clinicians now advocate that victims of trauma who have low but stable blood pressure should have delayed and controlled volume replacement at the time of surgery. ${ }^{10}$ This practice, however, should be reserved for those patients who are being cared for by an appropriate and experienced surgical team.

In the face of these difficulties, pericardiocentesis has been advocated as a reliable method to diagnose and treat tamponade. ${ }^{11}$ While this may be a truly life saving procedure, as in case 4 , it is not without attendant risk, and the number of patients in whom it is indicated is very small. If the blood in the pericardial cavity is clotted it cannot be adequately aspirated, a false negative result may be obtained, and the tamponade will not be relieved. There is also danger of ventricular puncture and damage to the coronary arteries. For these reasons most agree that this procedure is of little value in cardiac trauma. ${ }^{12}$

Subxiphoid pericardiotomy has been advocated, although it is a more invasive procedure and requires more surgical skill. ${ }^{13}$ It is more sensitive than pericardiocentesis but in some cases precipitous decompensation may occur, requiring immediate emergency thoracotomy for the control of bleeding.
Recently echocardiography has been used as a non-invasive diagnostic tool. ${ }^{14}$ However, though helpful in confirming the diagnosis, it cannot be relied on completely because the interpretation is operator dependent and false negatives occur. ${ }^{15}$

The role of emergency room thoracotomy remains controversial ${ }^{16}$ but it is still widely accepted that it is of value in penetrating trauma for patients in extremis ${ }^{17}$ and the best results are achieved in those suffering from cardiac tamponade. ${ }^{18}$

\section{CONCLUSION}

Traumatic pericardial tamponade is relatively rarely encountered in the United Kingdom and causes various diagnostic problems. Clinicians must have a high degree of clinical suspicion when dealing with victims of penetrating chest trauma, particularly if the injury lies in the "cardiac danger area". Although associated injuries need to be dealt with appropriately, the possibility of occult cardiac injury must always be kept in mind since a significant minority of patients remain stable and the signs of tamponade may be modified or absent because of compensatory mechanisms. Decompensation can occur rapidly during fluid replacement and unless the clinical condition of the patient dictates otherwise this should be carried out cautiously, with close monitoring. Echocardiography may be helpful in confirming the diagnosis by non-invasive means but is not completely reliable.

1 Sugg WL, Rea WJ, Ecker RR, Webb WR, Rose EF, Shaw RR Penetrating wounds of the heart: an analysis of 459 cases. J Thorac Cardiovasc Surg 1968;56:531-45.

2 Demetriades D, Van der Veen BW. Penetrating injuries to the heart: experience over two years in South Africa. J Trauma 1983;23:1034-41.

3 Jorden RC. Penetrating chest trauma. Emerg Med Clin North Am 1993;11:97-106.

4 Beck CS. Two cardiac compression triads. JAMA 1935;104 714-6.

5 Steedman DJ, Beard D. Preliminary analysis of the care of injured patients in five Scottish teaching hospitals. First report from the Scottish Trauma Audit Group (STAG). Health Bull 1995;53:55-65.

6 Bleetman A, Kasem H, Crawford R. Review of emergency thoracotomy for chest injuries in patients attending a UK Accident and Emergency department. Injury 1996;27: Accident

7 Borlase MC, Metcalf RK, Moore EE. Penetrating wounds to the anterior chest. Am J Surg 1986;152:649-53.

8 Karrel R, Shaffer MA, Franaszek JB. Emergency diagnosis, resuscitation and treatment of acute penetrating cardiac resuscitation and treatment of acute pen
trauma. Ann Emerg Med 1982;11:504-17.

9 Martin RR, Bickell WH, Pepe PE, Burch JM, Mattox KL. Prospective evaluation of preoperative resusitation in hypotensive patients with penetrating truncal injuries: a preliminary report. J Trauma 1992;33:354-62.

10 Westaby S. Resusitation in thoracic trauma. Br J Surg 1994 81:929-31.

11 Advanced trauma life support program handbook. Chicago: American College of Surgeons, 1993.

12 Siemens R, Polk HC, Gray LA, Fulton RL. Indications for thoracotomy following penetrating thoracic injury. Trauma 1977;17:493-500.

13 Trinkel JK, Toon RS, Franz JL, Arom KV, Grover FL. Affairs of the wounded heart: penetrating cardiac wounds. J Trauma 1979;19:467-71.

14 Reid CL, Kawanishi DT, Rahimtoola SH, Chandraratna PAN. Chest trauma: evaluation by two-dimensional echocardiography. Am Heart J 1987;11 3:971-6.

15 Freshman SP, Wisner DH, Weber CJ. 2-D Echocardiography: emergent use in the evaluation of penetrating precordial trauma. J Trauma 1991;31:902-6.

16 Arreola-Risa C, Rhee P, Boyle EM, Maier RV, Jurkovich Arreola-Risa C, Rhee P, Boyle EM, Maier RV, Jurkovich
GG, Foy HM. Factors influencing outcome in stab wounds GG, Foy HM. Factors influencing outcom

17 Asensio JA, Stewart BM, Murray J, Fox AH, Falabella A Gomez H, et al. Penetrating cardiac injuries. Surg Clin Gomez H, et al. Penetrating
North Am 1996;76:685-724.

18 Lewis G, Knottenbelt JD. Should emergency room thoracotomy be reserved for cases of cardiac tamponade?
Injury 1991;22:5-6. 